\title{
OsRACK1A, encodes a circadian clock-regulated WD40 protein, negatively affect salt tolerance in rice
}

\author{
Dongping Zhang ${ }^{1,4 \dagger}$, Yuzhu Wang ${ }^{1 \dagger}$, Jinyu Shen ${ }^{1}$, Jianfeng Yin ${ }^{1}$, Dahong $\mathrm{Li}^{3}$, Yan Gao ${ }^{1}$, Weifeng $\mathrm{Xu}^{2^{*}}$ \\ and Jiansheng Liang ${ }^{4^{*}}$ (D)
}

\begin{abstract}
The receptor for activated C kinase 1 (RACK1) is a WD40 type protein that is involved in multiple signaling pathways and is conserved from prokaryotes to eukaryotes. Here we report that rice RACK1A (OsRACK1A) is regulated by circadian clocks and plays an important role in the salt stress response. OsRACK1A was found to follow a rhythmic expression profile under circadian conditions at both the transcription and the translation levels, although the expression was arrhythmic under salt stress. Analysis of plant survival rates, fresh weight, proline content, malondialdehyde, and chlorophyll showed that suppression of OsRACK1A enhanced tolerance to salt stress. The ion concentration in both roots and leaves revealed that OsRACK1A-suppressed transgenic rice could maintain low $\mathrm{Na}^{+}$and high $\mathrm{K}^{+}$concentrations. Furthermore, OsRACK1A-suppressed transgenic rice accumulated significantly more abscisic acid ( $A B A)$ and more transcripts of ABA- and stress-inducible genes compared with the wild-type plants. Real-time quantitative polymerase chain reaction analysis revealed that many stress-related genes, including APETALA 2/Ethylene Responsive Factor (AP2/ERF) transcription factors, were upregulated in the OsRACK1A-suppressed transgenic rice line. We identified putative interactors of OsRACK1A, and found that OsRACK1A interacted with many salt stress-responsive proteins directly. These results suggest that OsRACK1A is regulated by circadian rhythm, and involved in the regulation of salt stress responses.
\end{abstract}

Keywords: OsRACK1A, Salt tolerance, Circadian, Rice

\section{Background}

The receptor for activated C kinase 1 (RACK1) is a member of the WD repeat-containing scaffold proteins and is conserved from prokaryotes to eukaryotes (Zhang et al., 2013). As a scaffolding protein, RACK1 protein interacts with many proteins and is involved in multiple signaling pathways (McCahill et al., 2002; Zhang et al., 2013). In plants, RACK1 is involved in diverse biological processes, such as seed germination, organ development, hormones and stress responses (Nakashima et al., 2008; Guo et al., 2009, 2011;

\footnotetext{
* Correspondence: wfxu@fafu.edu.cn; liangjs@sustc.edu.cn

${ }^{\dagger}$ Dongping Zhang and Yuzhu Wang contributed equally to this work.

${ }^{2}$ College of Life Sciences, Fujian Agriculture and Forestry University, Jinshan,

Fuzhou 350002, China

${ }^{4}$ Department of Biology, Southern University of Science and Technology,

Shenzhen 518055, China

Full list of author information is available at the end of the article
}

Zhang et al., 2014). Compared with the advances made from studies in metazoans and yeast, little is known about the molecular mechanisms of RACK1 in plants.

The Arabidopsis genome contains three RACK1 orthologues, RACK1A, RACK1B and RACK1C, which are $78 \%$ similar to mammalian RACK1 (Guo and Chen, 2008). Using loss-of-function mutants of RACK1A in Arabidopsis, Chen et al.(2006) found that AtRACK1A plays a role in several plant hormonal responses, including abscisic acid (ABA), gibberellin (GA), indole-3-acetic acid (IAA), and brassinosteroid (BR). There is direct and indirect evidence that $R A C K 1 s$ are involved in the regulation of plant tolerance to abiotic and biotic stresses (Kundu et al., 2013; Cheng et al., 2015). In Arabidopsis, the rack1a mutant strongly tolerates soil drying, compared with the wild-type (Zhang et al., 2013). Moreover, 
water loss in detached leaves and stomatal conductance of rack1 mutants were significantly lower than in the wild-type, and the endogenous ABA content of rackla mutants was higher than in the wild-type (Guo et al., 2009; Zhang et al., 2013). In addition, rack1a mutants were hypersensitive to ABA in serval developmental processes, such as seed germination, cotyledon greening, and root growth, and some ABA-responsive marker genes were upregulated in rackla mutants, while the RACK1 genes were downregulated by ABA (Guo et al., 2009). These results suggest that $R A C K 1$ functions as a negative regulator of $\mathrm{ABA}$ signaling and consequently enhances drought stress tolerance via ABA-dependent signaling in response to water stress in plants. Comparative proteomic analysis showed that the Arabidopsis RACK1C protein might play roles in regulating plant resistance to salt stress (Shi et al., 2011).

The rice genome contains two RACK1 homologous genes that are $\sim 80 \%$ similar to Arabidopsis RACK1 proteins at the amino acid level: OsRACK1A and OsRACK1B (Nakashima et al., 2008). Li et al. (2009) found that OsRACK1A-suppressed transgenic rice lines were more tolerant of soil drying, but the molecular mechanism remains unknown. Comparative phosphoproteomics studies revealed that the OsRACK1A protein is phosphorylated in response to exogenous $\mathrm{ABA}$ and drought treatment ( $\mathrm{He}$ et al., 2008; Ke et al., 2009). These findings suggested that OsRACK1A plays essential roles in ABA signaling and is involved in ABA-dependent stress responses. In addition to the involvement of RACK1 in the regulation of plant responses to abiotic stresses, it has been reported to function in plant innate immunity. Overexpression of OsRACK1A enhanced the production of reactive oxygen species (ROS) and increased resistance to blast fungus in rice (Nakashima et al., 2008). OsRACK1A regulated ROS levels not only in abiotic stress responses but also in the seed germination process. Previously, we found that OsRACK1A positively regulated seed germination by promoting $\mathrm{H}_{2} \mathrm{O}_{2}$ production and enhancing ABA catabolism (Zhang et al., 2014). Although RACK1 functions in ABA signaling in both rice and Arabidopsis, it is still unclear whether RACK1 is involved directly in ABA-dependent stress responses.

Circadian clocks are 24-h biological oscillators, which generally enable organisms to coordinate their activities with the external light/dark cycles by anticipating the onset of dawn or dusk. In mammals, RACK1 protein plays a crucial role in circadian clocks by interacting with BMAL1, a component of the heterodimeric CLOCK:BMAL1 circadian complex. However, the expression of RACK1 itself showed little or no circadian variation across the circadian cycle (Robles et al., 2010). In plants, no clock component has been reported to interact with RACK1 protein and whether plant $R A C K 1$ is involved directly in circadian clock regulation has yet to be investigated. In this study, our results indicated that OsRACK1A is a circadian rhythm gene and is involved in the response to salt stress. OsRACK1A-suppressed transgenic plants were hyposensitive to salt stress, compared with wild-type Nipponbare. OsRACK1A plays an important role in the tolerance to high salinity by regulating many stress-related genes and interacting directly with many stress-response proteins.

\section{Methods}

\section{Plant materials and stress treatment}

Rice (Oryza sativa L. cv. Nipponbare) was used as the wild-type (non-transgenic line; NTL) and in the generation of all transgenic plants. All transgenic rice lines were generated and kept in our laboratory. An OsRACK1A over-expressing transgenic line, OeTL3-8, and an RNA-interfered transgenic line, RiTL4-2, were used as experimental materials (Zhang et al., 2014). For $\mathrm{NaCl}$ treatment, 4-week-old hydroponic cultured rice plants were placed in different concentrations of $\mathrm{NaCl}$ solution $(100,150,200 \mathrm{mM})$ for $10-20 \mathrm{~d}$ and finally determined $150 \mathrm{mM} \mathrm{NaCl}$ treated with $18 \mathrm{~d}$ and recovered for $10 \mathrm{~d}$ was the best condition for identifying stress phenotypes. All the plants grew in a plant growth chamber (Conviron atc26, $16 \mathrm{~h}$ light/ $8 \mathrm{~h}$ dark, $30{ }^{\circ} \mathrm{C}$ day/ $22{ }^{\circ} \mathrm{C}$ night).

\section{Measurements of physiological index}

For the tolerance experiments, all rice plants were cultured in a plant growth chamber (Conviron atc26) $\left(30^{\circ}\right.$ $\mathrm{C}$ day $/ 22{ }^{\circ} \mathrm{C}$ night). The survival rate and fresh weight were calculated after $18 \mathrm{~d}$ of treatment with $150 \mathrm{mM}$ $\mathrm{NaCl}$ and recovery in normal conditions for another 10 d. Lipid peroxidation was determined by measuring the MDA content (Dhindsa and Matowe, 1981). The content of free proline in leaves was determined as described previously. (Bates et al., 1973) Chlorophyll was extracted from the leaves in $10 \mathrm{~mL}$ of $80 \%$ acetone for $16 \mathrm{~h}$ in the dark and was determined by measuring the absorbance at $652 \mathrm{~nm}$ (Arnon, 1949). To measure the $\mathrm{Na}^{+}$and $\mathrm{K}^{+}$ concentrations, 2-week-old hydroponic cultured rice seedlings were supplemented with $150 \mathrm{mM} \mathrm{NaCl}$ for 24 , 48 , or $72 \mathrm{~h}$. Shoots and roots were harvested at the indicated times and all physiological measurements were based on the procedure described by Yang et al. (2015). Measurement of water loss form detached leaves was performed as previously described by Zhang et al. (2015). The detached leaves of non-transgenic and transgenic rice lines were weighed at room temperature $(\sim$ $23{ }^{\circ} \mathrm{C}$ ) with $35 \%$ relative humidity. The endogenous ABA levels of rice leaves were measured based on the procedures described by Zhang et al. (2014). All of the 
data were subjected to Student's t-test analysis using SPSS ver. 13.0 (SPSS Company, Chicago, IL).

\section{Gene expression analysis}

The RNAprep Pure Plant Kit (cat. no. DP441; Tiangen Biotech) was used to extract total RNA from rice. Single-strand cDNAs were synthesized by using the HiScript Q RT SuperMix for qPCR kit (cat. no. R123; Vazyme). Transcript-level expression of each gene were measured by quantitative RT-PCR using a 7300 Real-Time PCR system (ABI), with the iTaq universal SYBR Green SuperMix (Bio-Rad), and normalized against the values obtained for housekeeping gene OsActin1 (LOC_Os03g50890). Three biological replicates were performed for each experiment. Additional file 1: Table S2 lists the qRT-PCR primer sequences. All of the data were subjected to Student's t-test analysis using SPSS ver. 13.0 (SPSS Company, Chicago, IL).

\section{Protein blot analysis}

Rice leaves of seedlings were ground in liquid nitrogen and homogenized in PBS buffer (cat. no. CW0040S; CoWin Bioscience) containing complete protease inhibitor cocktail (cat. no. 04693132001; Roche). To prepare total protein, the homogenate was centrifuged $(6000 \times g$, $30 \mathrm{~min}, 4{ }^{\circ} \mathrm{C}$ ) to remove cellular debris. Then, proteins were separated by sodium dodecyl sulfate polyacrylamide gel electrophoresis (SDS-PAGE) on 10\% gels and blotted onto polyvinylidene difluoride (PVDF) membranes. The antibodies used were anti- $\beta$-actin antibody (cat. no. CW0264M; CoWin Bioscience), anti-green fluorescence protein (GFP) antibody (cat. no. ab290; Abcam), and anti-OsRACK1A antibody (cat. no. AbP80112-A-SE; Beijing Protein Innovation).

\section{Co-IP assay}

To identify the OsRACK1A interaction proteins, $U B I:: G F P$ and $U B I:: G F P-O s R A C K 1 A$ transgenic rice were used for co-IP assays. Leaves from 4-week-old plants were harvested and ground in liquid nitrogen. Proteins were extracted with the buffer containing $50 \mathrm{mM}$ Tris (pH 7.5), 150 mM NaCl, 0.1\% IGEPAL CA-630, Proteinase Inhibitor Cocktail (cat. no. 04693159001; Roche) and Phophatase Inhibitor Cocktail (cat. no. 04906845001). The samples were centrifuged at $12,000 \mathrm{~g}$ for $15 \mathrm{~min}$ at $4{ }^{\circ} \mathrm{C}$ and the supernatant was incubated with anti-GFP magnetic beads (catalog no. D153-11; MBL) to overnight at $4{ }^{\circ} \mathrm{C}$ with gentle rotation. The beads were then washed four times with PBS. The immunoprecipitated proteins were eluted with $1 \mathrm{M}$ glycine ( $\mathrm{pH}$ 3.0). The presence of the corresponding proteins was detected by tandem liquid chromatograph-mass spectrometry (LC-MS/MS).

\section{Statistical analyses}

Statistical analyses were performed using IBM SPSS Statistics 21 software (Chicago, IL, USA), and analyzed with one-way ANOVA. $P<0.05$ was considered significant.

\section{Results \\ Expression of the OsRACK1A gene is controlled in a circadian-clock like manner}

Information retrieved from the public microarray database (ArrayExpress, Accession: E-MTAB-275) showed that a circadian rhythm in OsRACK1A mRNA abundance occurred under photocycling (12 h light/12 h dark; $12 \mathrm{~h}$ hot/12 h hot; LDHH), thermocycling $(12 \mathrm{~h}$ light/12 h light; $12 \mathrm{~h}$ hot/ $12 \mathrm{~h}$ cold; LLHC) or photocycling and thermocycling (12 h light/12 h dark; $12 \mathrm{~h}$ hot/12 h cold; LDHC) conditions (Additional file 1: Figure S1A). Another rice $R A C K 1$ homolog, OsRACK1B, exhibited similar expression patterns (Additional file 1: Figure S1B). To confirm whether the expression of OsRACK $1 A$ was controlled by a circadian clock, the expression of OsRACK1A in a 24-h period was measured. Quantitative RT-PCR analysis showed that the transcript level of OsRACK1A started accumulating with the onset of light and reached a maximum level $10 \mathrm{~h}$ after the lights were switched on (ZT0 and ZT24) and then the transcript level declined gradually and reached a minimum $6 \mathrm{~h}$ after the lights were switched off (ZT16 and ZT40, Fig. 1a). We also examined levels of OsRACK1A protein during the light/dark cycle using western blot analysis and the results revealed that OsRACK1A protein accumulated in the light (ZT0 to ZT14) and declined in the dark (ZT16 to ZT22, Fig. 1b). Moreover, we tested the expression of OsRACK1A under the constant light conditions and found that $O s R A C K 1 A$ also displayed rhythmic expression (Additional file 1: Figure $\mathrm{S} 1 \mathrm{C})$.

\section{Overexpression of OsRACK1A delays the time of heading}

Some circadian clock-controlled genes have been reported to be involved in photoperiodic flowering regulation (Xue et al., 2008; Ishikawa et al., 2011; Matsubara et al., 2011). To investigate whether OsRACK1A plays a role in photoperiod-controlled heading, we generated several OsRACK1A RNA-interference (RNAi) and overexpressing lines (Li et al., 2009). From these transgenic rice lines, we chose the stable downregulated RNA-interfered transgenic line RiTL4-2, and the upregulated overexpressed transgenic line OeTL3-8. Compared with the non-transgenic line (NTL), the OsRACK1A protein level was higher in OeTL3-8 and lower in RiTL4-2, measured by Western blot analysis using an OsRACK1A-specific antibody (Fig. 1c). This 


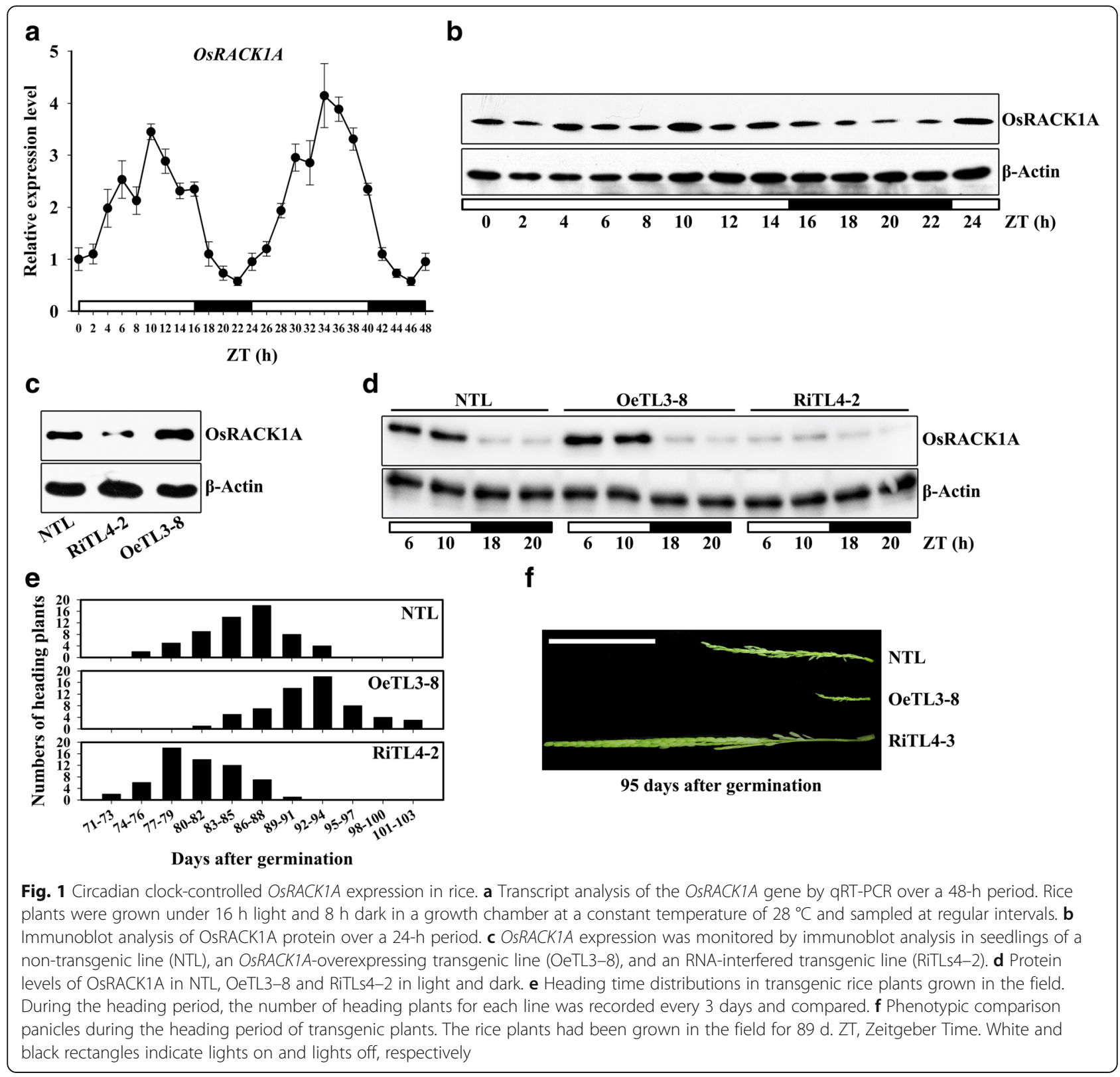

differential protein expression patterns of the three genotypes was occurred only in the light, whereas OsRACK1A protein was nearly undetectable in the dark (Fig. 1d). The heading date of field-grown plants was recorded and OeTL3-8 had a heading date nearly 1 week later than NTL, whereas RiTL4-2 showed a heading time approximately 1 week earlier than NTL (Fig. 1e). The panicles phenotypes of field-grown plants at $95 \mathrm{~d}$ after germination are shown in Fig. 1f.

$\mathrm{NaCl}$ treatment affects expression of the OsRACK1A gene To investigate the expression profile of the OsRACK1A gene under salt stress, 2-week-old hydroponic cultured rice seedlings were exposed to $150 \mathrm{mM} \mathrm{NaCl}$ for different times and the transcript-level expression of this gene was monitored using quantitative RT-PCR. The OsRACK1A expression pattern changed significantly in response to $\mathrm{NaCl}$ treatment. The transcript level of OsRACK1A accumulated from ZT0 to ZT12 under both salt stress and control conditions, but expression of OsRACK1A was slightly higher under control than under salt stress conditions (Fig. 2a). Under normal conditions, the expression of OsRACK1A behaved like a circadian clock; when treated with $\mathrm{NaCl}$, however, the transcription level of OsRACK1A first increased to a relatively high level and then maintained this level throughout the experiment (Fig. 2a), which means that the circadian clock of OsRACK1A expression disappeared when exposed to salt stress. The 


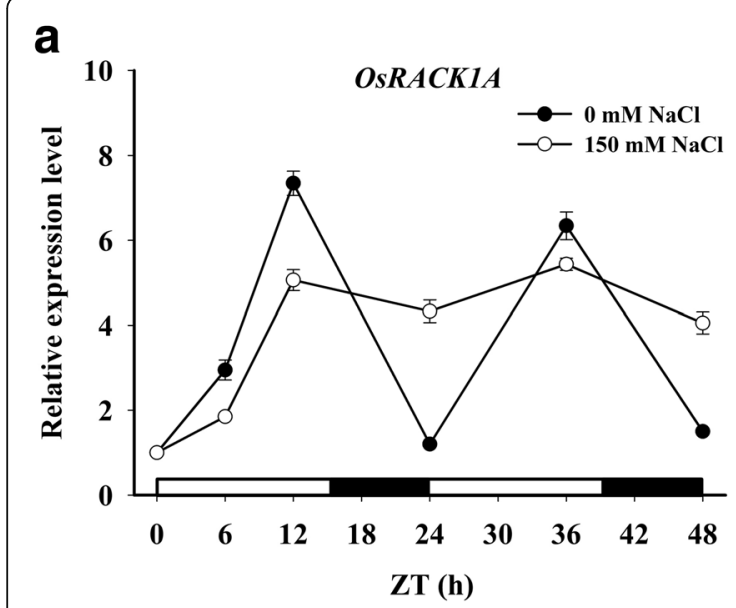

C

Anti-OsRACK1A Anti-GFP
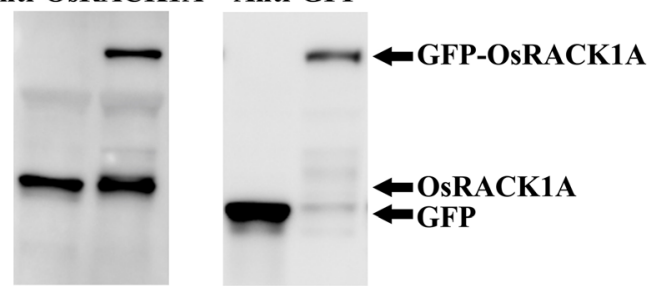

GFP
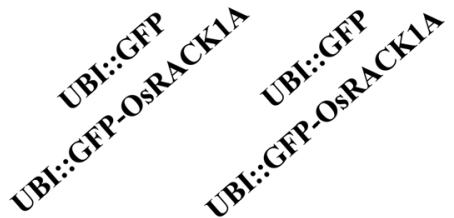

b

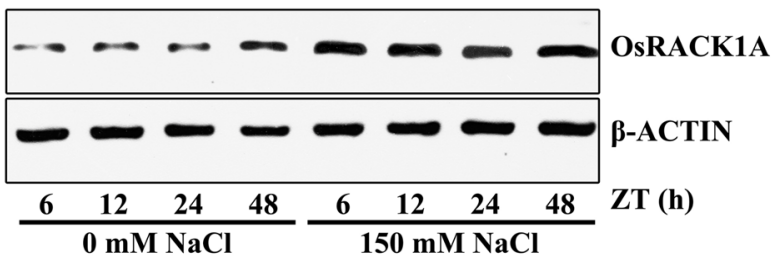

d

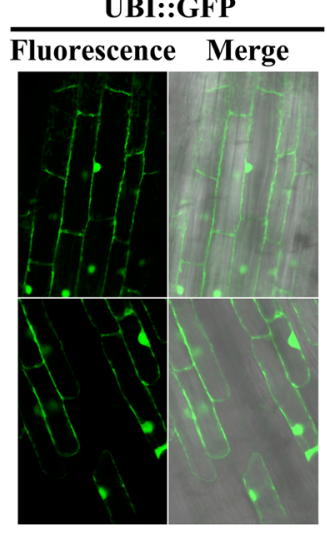

UBI::GFP-OsRACK1A

Fluorescence Merge

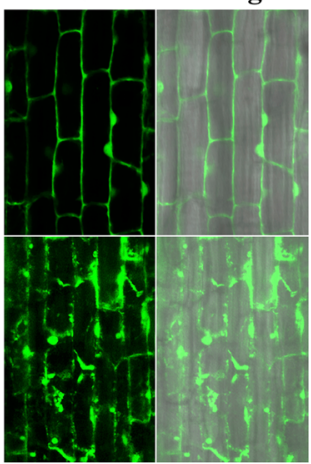

$0 \mathrm{mM} \mathrm{NaCl}$

$150 \mathrm{mM} \mathrm{NaCl}$

Fig. 2 Salt stress-controlled OsRACK1A expression in rice. a Transcript analysis of the OsRACK1A gene by qRT-PCR for a 48-h period under 0 and $150 \mathrm{mM} \mathrm{NaCl}$ treatment. b Immunoblot analysis of OsRACK1A protein for a 24-h period under 0 and $150 \mathrm{mM} \mathrm{NaCl}$ treatment. c GFP, OsRACK1A and a GFP-OSRACK1A fusion protein were monitored by immunoblot analysis in seedlings of UBI-promoted GFP and GFP-OSRACK1A transgenic rice. d GFP fluorescence was examined in roots of UBI-promoted GFP and GFP-OsRACK1A transgenic rice under 0 and $150 \mathrm{mM} \mathrm{NaCl}$ treatment for 6 h. ZT, Zeitgeber Time. White and black rectangles indicate lights on and lights off, respectively

similar expression pattern of OsRACK1A was shown under both light/dark cycle and constant light conditions with $\mathrm{NaCl}$ treatment (Additional file 1: Figure S1B). Interestingly, the protein level of OsRACK1A increased and was significantly higher than in the untreated control at 6 , 12, 24, and $48 \mathrm{~h}$ after the onset of salt stress (Fig. 2b), whereas the transcript levels of OsRACK1A were lower at ZT6 and ZT12 in the $\mathrm{NaCl}$ treatment than under control conditions (Fig. 2a).

Therefore, we suspected that OsRACK1A protein levels were under post transcriptional and/or translational control. To test this, transgenic rice plants were generated that constitutively expressed GFP-OsRACK1A. As shown in Fig. 2c, the GFP-OsRACK1A fusion protein was detected in ubiquitin-promoted GFP-OsRACK1A transgenic plants, whereas the GFP protein was detected in $U B I:: G F P$ transgenic plants. Figure $2 \mathrm{~d}$ shows fluorescence images of GFP-OsRACK1A transgenic plants in the presence or absence of $150 \mathrm{mM} \mathrm{NaCl}$ for $6 \mathrm{~h}$. Control plants containing
GFP alone showed no change in subcellular localization in response to salt stress (Fig. 2d). Furthermore, before salt treatment, plants containing GFP-OsRACK1A exhibited fluorescence that was detectable in the cytosolic fraction, as well as in the plasma membrane and nuclei. After treatment with $150 \mathrm{mM} \mathrm{NaCl}$, GFP fluorescence from the GFP-OsRACK1A fusion was enhanced and appeared diffusely in the cytosol (Fig. 2d). These results supported the premise that OsRACK1A protein was controlled by post-transcriptional and/or translational regulation and accumulated under salt stress.

\section{OsRACK1A negatively regulates salt tolerance}

Because both mRNA and protein levels of OsRACK1A were induced by the high-salinity treatment, we used the OsRACK1A-overexpressing (OeTL3-8) and RNAi (RiTL4-2) lines to determine whether these different transgenic lines showed differences in performance under salt stress versus the NTL. Under normal conditions, 
transgenic plants showed no significant difference in growth versus the NTL. When 4-week-old plants were stressed with $150 \mathrm{mM} \mathrm{NaCl}$ for $18 \mathrm{~d}$, the RiTL4-2 plants had more green leaves than the OeTL3-8 or NTL plants. After $18 \mathrm{~d}$ of high-salt treatment, all plants were subjected to normal irrigation (without salt stress) to allow recovery. Only RiTL4-2 plants survived and resumed growth, forming new tillers, while OeTL3-8 and NTL plants died during the 10-d recovery period (Fig. 3a). Twenty pots of plants were counted and the data showed that the survival rate of RiTL4-2 plants was $\sim 50 \%$, whereas only $\sim 20 \%$ of NTL plants survived. The lowest survival rate $(<10 \%)$ was observed in OeTL3-8 plants (Fig. 3b). After $10 \mathrm{~d}$ of high-salinity treatment, the fresh weight of NTL was significantly higher than that of OeTL3-8 and lower than that of RiTL4-2 (Fig. 3c). These results supported the notion that OsRACK1A increases the salt stress response in rice.

To evaluate the effects of salt stress on cell membranes, 4-week-old seedlings were treated with $150 \mathrm{mM}$ $\mathrm{NaCl}$ for 24, 48, or $72 \mathrm{~h}$ and the malondialdehyde (MDA) content was measured. The RiTL4-2 plants had lower MDA contents, whereas OeTL3-8 contained more MDA than NTL under salt stress (Fig. 3d). The MDA contents indicated that cell membrane stability was reduced in the OsRACK1A-overexpressing line and increased in the OsRACK1A-RNAi line, versus the NTL under high-salinity stress. Most plants showed increased proline contents under salt-stress conditions, which was considered to be correlated with their stress resistance. In this study, the content of proline was increased after salt stress in plants. Compared with NTL plants, RiTL4-2 plants accumulated higher levels of proline and OeTL3-8 accumulated lower levels under $150 \mathrm{mM} \mathrm{NaCl}$ treatment (Fig. 3e). It is known that salt stress causes chlorophyll degradation. We examined the chlorophyll content of rice plants exposed to $150 \mathrm{mM} \mathrm{NaCl}$. As shown in Fig. 3f, the chlorophyll content declined after salt stress. Compared with NTL plants, chlorophyll contents in RiTL4-2 plants were higher, whereas those in OeTL3-8 were lower under $150 \mathrm{mM} \mathrm{NaCl}$ treatment. These results indicated that suppression of OsRACK1A enhanced salt-stress tolerance.

OsRACK1A regulates $\mathrm{Na}^{+}$and $\mathrm{K}^{+}$levels under salt stress An important aspect of salt tolerance is the avoidance of $\mathrm{Na}^{+}$accumulation, and $\mathrm{K}^{+}$homeostasis is important for this process (Zhu, 2003). Four-week-old hydroponically grown transgenic and non-transgenic rice plants were subjected to $150 \mathrm{mM} \mathrm{NaCl}$ for $72 \mathrm{~h}$. Subsequently, the leaves and roots were harvested at $0 \mathrm{~h}$ (before stress) and after 24,48 , and $72 \mathrm{~h}$ of salt stress, to measure $\mathrm{Na}^{+}$
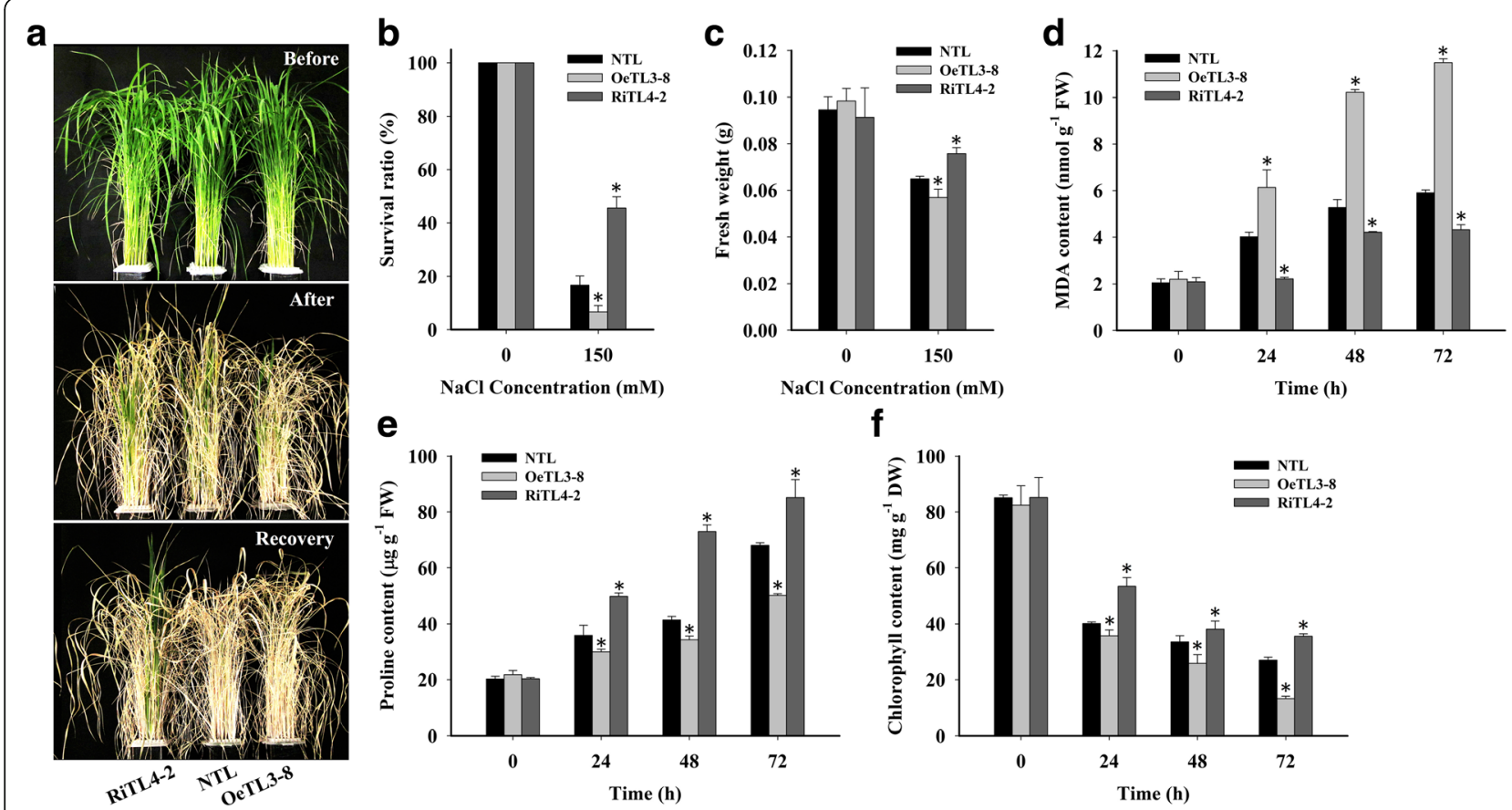

Fig. 3 OsRACK1A negatively regulates salt tolerance. a Comparison of the non-transgenic line (NTL), the OsRACK1A-overexpressing transgenic line (OeTL3-8), and the RNA-interfered transgenic line (RiTLs4-2) under $150 \mathrm{mM} \mathrm{NaCl}$ for $18 \mathrm{~d}$ (salt-stress recovery for $10 \mathrm{~d}$ ). $\mathbf{b}$ Survival rate of plants after $150 \mathrm{mM} \mathrm{NaCl}$ treatment and recovery. c Fresh weight of plants after $150 \mathrm{mM} \mathrm{NaCl}$ treatment. $\mathbf{d}$ to $\mathbf{f}$ Contents of proline, MDA, and chlorophyll under $150 \mathrm{mM} \mathrm{NaCl}$ for 0, 24, 48 and $72 \mathrm{~h}$. Sixty seedlings per genotype (twenty seedlings for each biological replicate) were used. Data shown are the means \pm SE of three biological replicates. An asterisk indicates a significant difference $(P<0.05)$ versus stressed NTL 
and $\mathrm{K}^{+}$contents. Before the $\mathrm{NaCl}$ treatment, $\mathrm{Na}^{+}$and $\mathrm{K}^{+}$levels in both shoots and roots of the plants with the three different genotypes were similar. The level of $\mathrm{Na}^{+}$ increased continuously under salt stress in all plant lines tested. However, RiTL4-2 plants accumulated significantly less $\mathrm{Na}^{+}$than the NTL, whereas OeTL3-8 contained more $\mathrm{Na}^{+}$in both leaves and roots (Fig. 4a). In contrast to the $\mathrm{Na}^{+}$levels, the $\mathrm{K}^{+}$levels declined in the leaves and roots of all plant lines tested during salt stress. At $72 \mathrm{~h}$ of salt stress, the content of $\mathrm{K}^{+}$in RiTL4-2 plants was higher than in NTL, whereas OeTL3-8 contained less $\mathrm{K}^{+}$than NTL in leaves and roots (Fig. 4b). These results suggested that RiTL4-2 plants might have the ability to avoid $\mathrm{Na}^{+}$accumulation

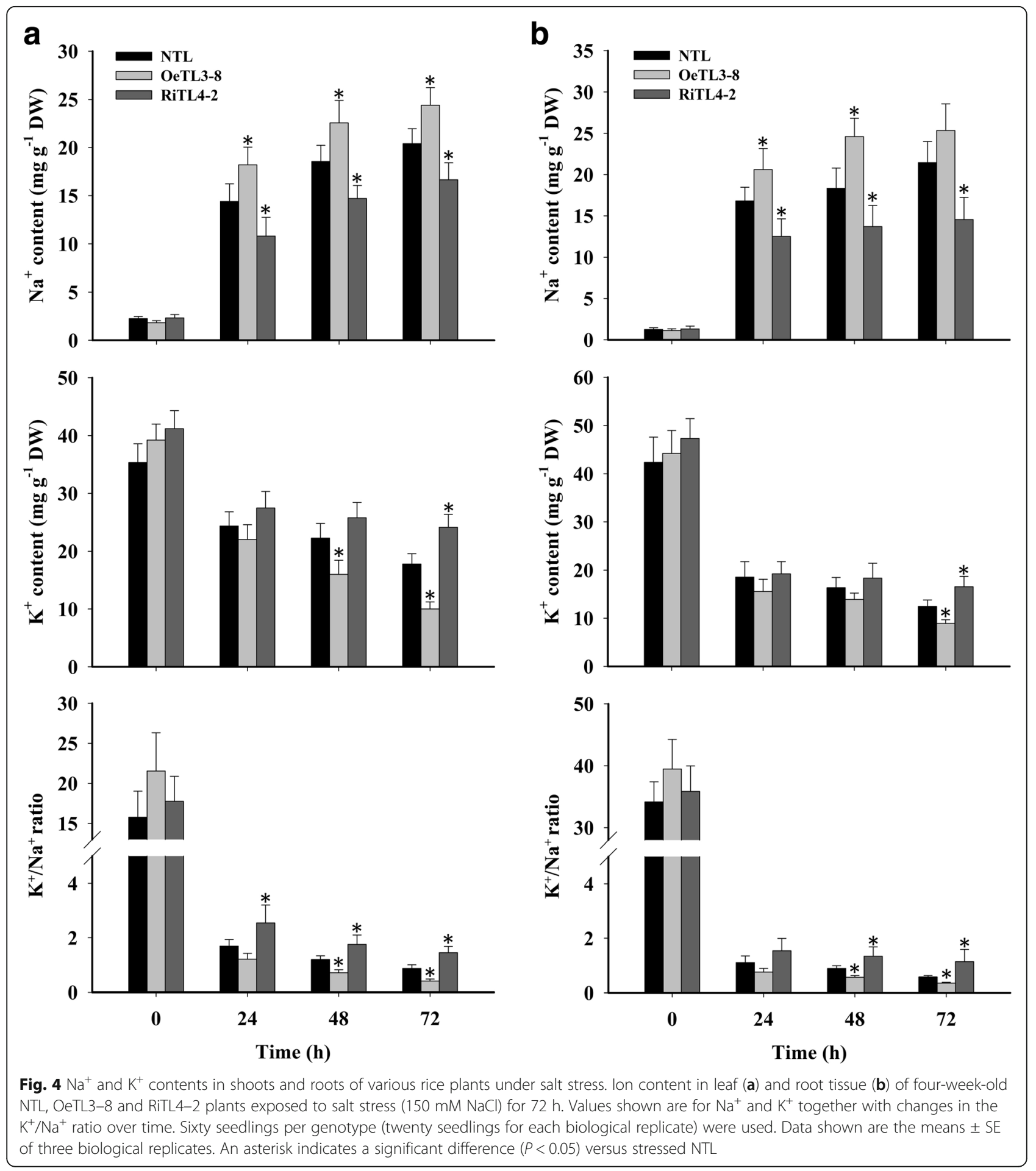


and maintain $\mathrm{K}^{+}$homeostasis under high-salinity stress. It is generally accepted that the ability to maintain a high $\mathrm{K}^{+} / \mathrm{Na}^{+}$ratio contributes to salt tolerance in plants (Zhu, 2003). A decreasing $\mathrm{K}^{+} / \mathrm{Na}^{+}$ratio was detected in the roots and leaves of all plants under salt stress. However, a markedly higher $\mathrm{K}^{+} / \mathrm{Na}^{+}$ratio was observed in both shoots and roots of the RiTL4-2 plants than those of the NTL and OeTL3-8 plants, whereas no significant difference was observed under normal conditions (Fig. 4a, b). These results imply that OsRACK1A negatively regulates rice tolerance of $\mathrm{NaCl}$ largely by controlling the $\mathrm{Na}^{+}$and $\mathrm{K}^{+}$accumulation in cells.

OsRACK1A regulates endogenous $A B A$ content and $A B A-$ responsive genes under salt stress

The phytohormone ABA is a crucial regulator of plant growth and development, and plays a critical role in controlling adaptive plant responses to environmental stresses, such as drought, high salt stress, cold stress, and pathogen infection (Cutler et al., 2010; Umezawa et al., 2010). ABA accumulation and some ABA biosynthesis genes are upregulated by $\mathrm{NaCl}$, drought, and cold stress (Cutler et al., 2010). We determined the endogenous ABA content of leaves under salt stress and found that the endogenous ABA content was significantly lower in OeTL38 , and significantly higher in RiTL4-2 compared with that of NTL (Fig. 5a). The ABA content induced under stress conditions is regulated by the ABA biosynthesis 9-cis-epoxycarotenoid dioxygenase (NCED) genes (Xiong et al., 2002). Our preliminary analysis showed that the transcript level of the OsNCED4 and OsNCED5 genes was dramatically induced under salt stress (Additional file 1: Figure S2). This study showed the transcript level of OsNCED4 in RiTL4-3 was $~ 1.5$-fold those in NTL and OeTL3-8, and the transcript level of OSNCED5 was much higher in RiTL4-3 than in NTL and OeTL3-8 under stress conditions (Fig. 5b).

Next, we determined the transcript expression of three ABA response genes- OsRAB16A, OsLEA3 and OsLIP9 - under salt stress. As shown in Fig. $5 \mathrm{c}$, without $\mathrm{NaCl}$ treatment, the transcript levels of OsRAB16A, OsLEA3 and OSLIP9 showed no significant difference between wild-type and transgenic plants. Upon $150 \mathrm{mM} \mathrm{NaCl}$ treatment, transcripts of these genes accumulated significantly in all three genotypes, while RiTL4-3 accumulated more transcripts than NTL and OeTL3-8 in response to salt stress (Fig. 5c). Because ABA is a key regulator of stomatal opening and closure, water loss from the detached leaves of NTL, OeTL3-8 and RiTL42 was compared. As shown in Fig. 5d, water loss in RiTL4-2 was much slower than in NTL and OeTL3-8. These results suggested that OsRACK1A negatively regulated the expression of ABA-dependent stress-inducible genes under salt treatment conditions.
OsRACK1A significantly changes expression of salt stressrelated genes in rice plants

Next, we evaluated the expression of stress-related genes in NTL, OeTL3-8, and RiTL4-2 plants grown under both control and salt-stress conditions by real-time qPCR. As shown in Fig. 6a, under control conditions, the dehydration-responsive element-binding protein 1 (DREB1) genes, OsDREB-A, $-1 B,-1 C,-1 E,-1 G$ and $-1 H$, and the stress-related APETALA2/Ethylene Responsive Factor (AP2/ERF) gene AP59 were upregulated in RiTL4-2 and downregulated in OeTL3-8, in comparison with NTL. When treated with $150 \mathrm{mM} \mathrm{NaCl}$ for $24 \mathrm{~h}$, the transcript levels of OsDREB1A, $1 B,-1 C,-1 E$, $-1 G$, and OsAP59 in RiTL4-2 were higher than those in NTL, and the expression of OsDREB1A, $-1 \mathrm{C}$ and OsAP59 was lower in OeTL3-8 (Fig. 6a).

We selected another seven salt stress-responsive genes (OsMYB2, SNAC1, OsTCP19, OsTPS1, OsMAPK5, OsSIK1, and OsCPK4) that have been reported to improve salt-stress tolerance (Xiong and Yang, 2003; $\mathrm{Hu}$ et al., 2006; Ouyang et al., 2010; Li et al., 2011; Yang et al., 2012; Campo et al., 2014; Mukhopadhyay and Tyagi, 2015). The expression levels of these genes were all upregulated significantly in RiTL4-2, while the expression levels of OsMAPK5, OsMYB2 and SNAC1 were downregulated significantly in OeTL3-8. OsRMC has been reported to be a negative regulator of the salt-stress response in rice (Zhang et al., 2009; Serra et al., 2013) and the expression of OsRMC was downregulated in RiTL4-2 (Fig. 6b). Similar expression profile of these genes occurred under salt-stress conditions (Fig. 6b). These results may partially explain the phenotype of RiTL4-2 plants under stress conditions.

\section{OsRACK1A interacts with salt-stress response proteins}

As a scaffold protein, RACK1 interacts with numerous proteins and plays a critical role in many fundamental physiological processes, including stress responses (Zhang et al., 2013). In this study, we used co-immunoprecipitation (co-IP) to identify novel proteins that interact with OsRACK1A under both normal and salt-stress conditions. As shown in Fig. 7a and Additional file 2: Table S1, 12 and 20 proteins were detected to interact with OsRACK1A directly or indirectly in normal and stress conditions, respectively. Of these 32 identified proteins, two (Os07g37760 and Os01g25610) interacted with OsRACK1A in both normal and salt-stress conditions (Fig. 7a). Nine of these genes responded to $\mathrm{NaCl}$ treatment (Additional file 1: Figure S3). We also used the yeast two-hybrid assay to confirm these interactions and ultimately found that six of the identified proteins interacted directly with OsRACK1A (Fig. 7b). Interestingly, these six proteins were all identified in 


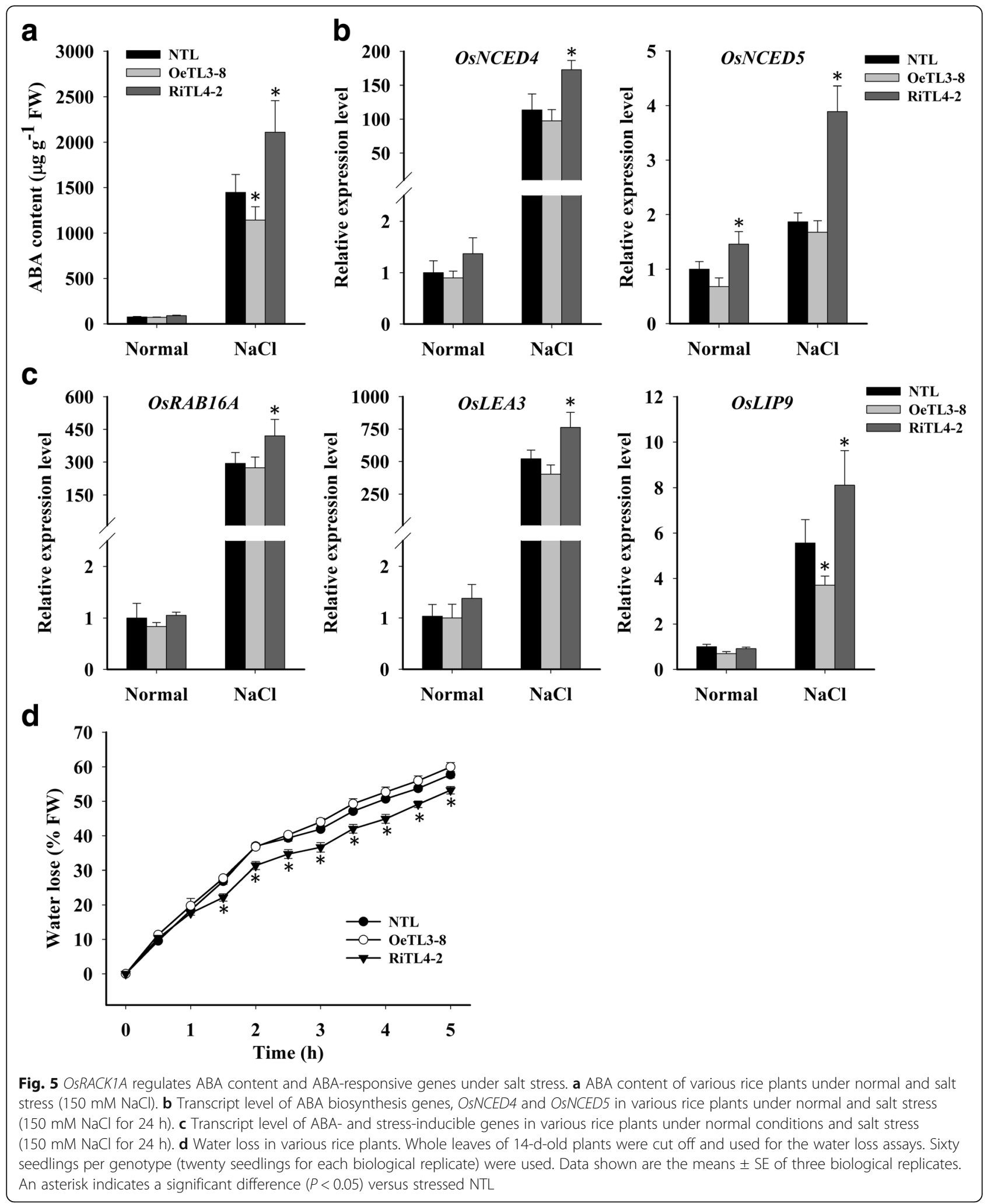

salt-stress conditions by co-IP assay and their mRNA levels were all downregulated with salt treatment (Fig. 7a, Additional file 1: Figure S3). The mRNA expression of these six OsRACK1A interacting proteins was also detected in NTL, OeTL3-8, and RiTL4-2 under both normal and salt-stress conditions. The transcript levels of 


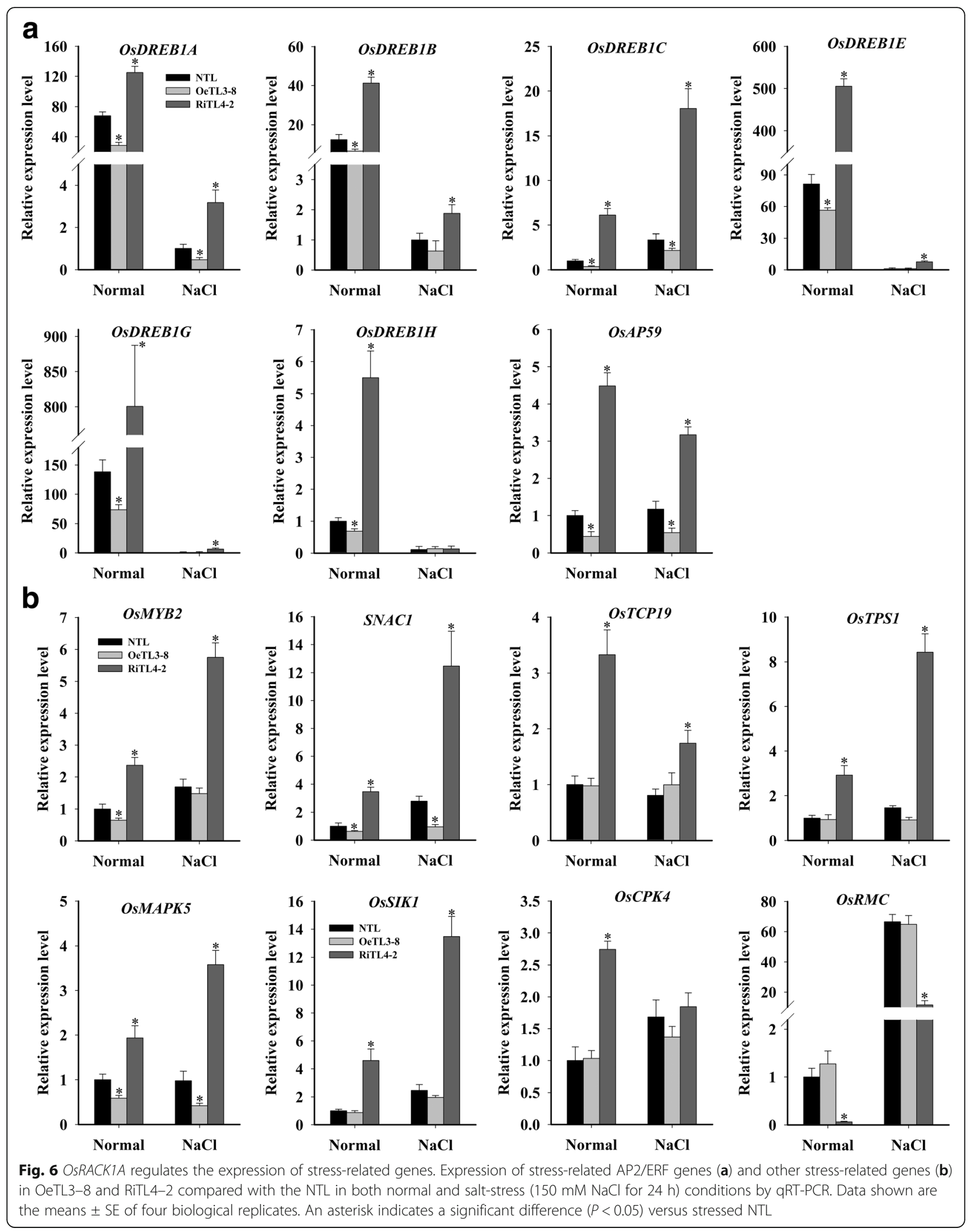



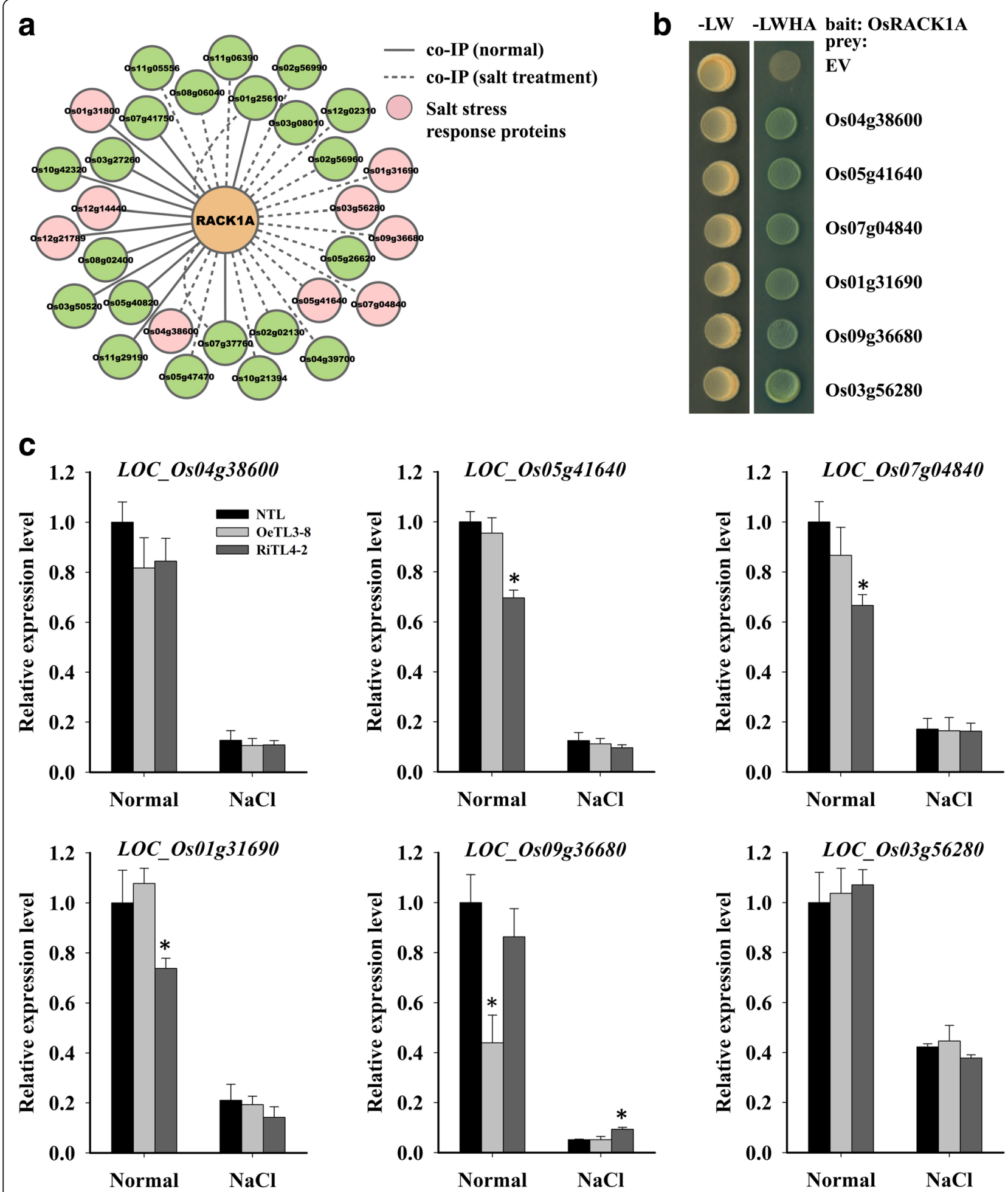

Fig. 7 OsRACK1A directly interacts with stress-response proteins. a OsRACK1A interaction proteins screening using co-IP in both normal and salt stress (150 mM NaCl for $24 \mathrm{~h}$ ) conditions. b Verifying the protein interactions by yeast two hybrid assay. c Quantitative RT-PCR analysis of the expression of OsRACK1A interactors in response to salt stress $(150 \mathrm{mM} \mathrm{NaCl}$ for $24 \mathrm{~h}$ ). Data shown are the means \pm SE of four biological replicates. An asterisk indicates a significant difference $(P<0.05)$ versus stressed NTL 
Os05g41640, Os07g04840, and Os01g31690, which encode phosphoglycerate kinase, PsbP, and oxygen-evolving enhancer protein 1, respectively, were lower in RiTL4-2 compared with NTL and OeTL3-8 in normal conditions, whereas no significant change in the expression of these genes was observed in NTL and transgenic plants after $\mathrm{NaCl}$ treatment (Fig. 7c). The Os09g36680, which encodes a ribonuclease $\mathrm{T} 2$ family domain containing protein, was downregulated in OeTL3-8 with no treatment and up-regulated in RiTL4-2 under salt treatment (Fig. 7c). These results indicated that OsRACK1A regulates stress responses by interacting directly with many stress related proteins.

\section{Discussion}

RACK1 is a highly conserved scaffold protein that is expressed ubiquitously (Zhang et al., 2013). RACK1 is involved in multiple signaling pathways, including growth and development and responses to external environmental stresses (McCahill et al., 2002; Zhang et al., 2013). However, the molecular mechanisms of RACK1 in plants is still in its infancy. In plant, $R A C K 1$ is involved in the regulation of cell proliferation and elongation, and the responses to plant hormones and environmental factors (Chen et al., 2006; Nakashima et al., 2008; Guo et al., 2009; Li et al., 2009; Zhang et al., 2013; Zhang et al., 2014). The rice genome contains two RACK1 ortholog genes, OsRACK1A and OsRACK1B (Nakashima et al., 2008). Although OsRACK1A and OsRACK1B are similar, OsRACK1A transcript levels are always significantly higher than those of OSRACK1B in leaves, roots, and mature seeds (Zhang et al., 2014). Previously, we reported that OsRACK1A negatively regulated the response of seed germination to exogenous ABA and the suppression of OsRACK1A improved drought tolerant in rice ( $\mathrm{Li}$ et al., 2009; Zhang et al., 2014). In the present study, we showed that OsRACK1A negatively regulated salt stress tolerance and sought to explore the molecular mechanism(s) involved.

A circadian oscillator controls the timing of several physiological functions in living organisms. In plants, processes controlled by a circadian clock include the photoperiodic induction of flowering, rhythmic leaf movements and stomatal opening (Thines and Harmon, 2011). Recent research also suggests that a circadian clock may contribute to plant fitness, enhancing their ability to tolerate abiotic stress (Grundy et al., 2015). In maize, transcripts of many stress related genes exhibits a diurnal cycling pattern (Hayes et al., 2010; Khan et al., 2010). Some salt stress-responsive genes, such as SOS1, RD29A and $D R E B 2 A$, exhibit a 24-h period of expression in Arabidopsis, suggesting that salt tolerance may also be affected by the circadian clock (Park et al., 2016a). In some cases, other stress, such as cold and drought, modifies the transcription pattern of a major portion of genes showing diurnal oscillation (Wilkins et al., 2010; Jończyk et al., 2017). Resent evidence indicates that plants respond to salt stress more strongly during the day than at night and salt-induced expression of RD29A and SOS1 was much higher in the daytime than at night (Park et al., 2016b). We found that both mRNA and protein levels of OsRACK1A exhibits a diurnal cycling pattern, and much higher during the day than at night (Fig. 1a, b). However, expression of OsRACK1A increased under salt stress and remained high in both the light and dark (Fig. 2a, b). It might be that higher expression levels of OsRACK1A in day caused more damage under salt stress.

In rice, OsRACK1A protein is phosphorylated under ABA and drought treatment, although the kinase responsible was not identified ( $\mathrm{He}$ and $\mathrm{Li}, 2008$; $\mathrm{Ke}$ et al., 2009). Recently, Urano et al. (2015) showed that Arabidopsis RACK1A (AtRACK1A) is also phosphorylated by an atypical serine/threonine protein kinase, WITH NO LYSINE 8 (WNK8), and phosphorylation of AtRACK1A rendered it unstable. Interestingly, in this present study, we found that OsRACK1A protein was controlled by post-transcriptional or translational regulation and consequently accumulated under salt stress. These results led us to the hypothesize that phosphorylation of OsRACK1A does not reduce the protein stability in rice and RACK1 protein may play distinct roles in different plant species. Guo and Sun (2017) found that sumoylation of Arabidopsis RACK1B (AtRACK1B) increased AtRACK1B stability and its tolerance to ubiquitin-mediated degradation in the $\mathrm{ABA}$ response, and consequently enhanced the interaction between RACK1B and RAP2.6. Combined, these findings illustrate that protein stability controlled by post-transcriptional modification is a critical regulatory mechanism for RACK1 in both Arabidopsis and rice.

In Arabidopsis, the clock component GIGANTEA (GI) is involved in salt-stress responses (Kim et al., 2013). Similar to OsRACK1A, GI transcription is under circadian control and peaked at 8-10 $\mathrm{h}$ after the start of the day (Park et al., 1999). Under normal conditions, GI interacts with SOS2, a key component of the SOS pathway, preventing the interaction between SOS2 and SOS3. Under salt stress conditions, GI is degraded and the free SOS2/SOS3 complex activates SOS1, a $\mathrm{Na}^{+} / \mathrm{H}^{+}$antiporter, to export sodium $\left(\mathrm{Na}^{+}\right)$ions from cells (Kim et al, 2013). In the present study, OsRACK1A also negatively regulated $\mathrm{Na}^{+}$ accumulation and subsequently maintained a low $\mathrm{K}^{+} / \mathrm{Na}^{+}$ ratio in rice seedlings under $\mathrm{NaCl}$ stress (Fig. 4a, b). We investigated the proteins that interact with OsRACK1A and identified six salt-stress suppressed proteins that interacted with OsRACK1A directly (Fig. 7a, b). Unfortunately, none of these proteins were reported to be directly involved in salt-stress responses and the relationship 
between OsRACK1A and the $\mathrm{Na}^{+} / \mathrm{H}^{+}$antiporter is still unclear. In eukaryotes, RACK1 regulates various signaling pathways and cellular processes through its interaction with numerous signaling proteins (Zhang et al., 2013). For example, OsRACK1A binds the active form of Rac1 and interacts with the $\mathrm{N}$ terminus of Rboh, RAR1, and SGT1, to form a complex in rice innate immunity (Nakashima et al., 2008). Similarly, OsRACK1A may form a complex with these salt-stress responses proteins, and active downstream molecules, such as salt-stress relative transcription factor. Future studies will reveal whether these OsRACK1A-interaction proteins are involved in salt-stress response.

Under high-salt-stress conditions, a key plant stress-signaling hormone, ABA, and numerous ABA-induced stress-responsive genes products accumulate (Yoshida et al., 2014). The NCED genes are known to encode key enzymes in ABA biosynthesis in plants (Nambara and Marion-Poll, 2005). In Arabidopsis, AtNCED3 is induced by drought and high salinity, and the overexpression of AtNCED3 in transgenic plants enhanced dehydration stress tolerance (Iuchi et al., 2001). Five NCED genes (OsNCED1-5) have been identified in the rice genome (Zhu et al., 2009). The qPCR analysis showed that the OsNCED4 and OsNCED5 were induced strongly under salt stress (Additional file 1: Figure S2), suggesting that transcriptional regulation of the OsNCED4 and OsNCED5 genes may be involved in salt-induced ABA accumulation in rice. Previous study has showed that OsRACK1A negatively regulated the response of seed germination to exogenous ABA (Zhang et al., 2014). Here we showed that the expression levels of OsNCED4 and OsNCED5 were higher in the OsRACK1A-suppressed line (RiTL4-2) than the non-transgenic line and the OsRACK1A-expressing line (OeTL3-8; Fig. 5b). Additionally, the ABA content was higher in RiTL4-2 than in NTL and OeTL3-8 (Fig. 5a), suggesting that the OsRACK1A protein suppressed ABA accumulation under salt stress by regulating the expression of ABA biosynthesis genes. Some typical ABA-dependent stress-inducible genes, such as OsRAB16A, OsLEA3 and OsLIP9, show higher mRNA levels in RiTL4-2, indicating that OsRACK1A is involved in ABA-dependent stress pathways.

The AP2/ERF transcription factor superfamily is involved in responses to biotic and abiotic stresses, the regulation of metabolism, and developmental processes in various plant species (Dossa et al., 2016). We selected some $A P 2 / E R F$ genes (OsDREB-1A, 1B, -1C, -1E, -1G, $-1 H$ and OsAP59) and found that these AP2/ERF genes were all upregulated in RiTL4-2 and some of them were downregulated in OeTL3-8 (Fig. 6a). Many of the upregulated $A P 2 / E R F$ genes have been reported to play roles in salt-stress tolerance. Transgenic plants overexpressing
OsDREB1B showed higher tolerances to drought, high salt, and freezing stresses (Dubouzet et al., 2003; Qin et al., 2006; Mao and Chen, 2012). The OsAP59 gene was found to be induced after exposure to drought and high-salt conditions, and constitutive expression of OsAP59 in rice increased the tolerance to drought and high salinity during vegetative development (Oh et al., 2009). Some of these AP2/ERF genes, such as OsAP59, were not induced by ABA (Oh et al., 2009). These results suggested that OsRACK1A is also involved in ABA-independent signaling in response to stress in rice. We found some other stress-related transcription factors, such as OsMYB2, SNAC1 and OsTCP19 were upregulated in OsRACK1A suppressed-expression plants in both normal and stress condition (Fig. 6b). OsMYB2-overexpressing plants were reported showing more tolerant to salt, cold, and dehydration stresses and more sensitive to abscisic acid than wild-type plants (Yang et al., 2012). Interestingly, two core circadian clock components, CIRCADIAN CLOCK ASSOCIATED 1 (CCA1) and LATE ELONGATED HYPOCOTYL 1 (LHY1), are also belone to MYB transcription factor family and involved in cold stress responses (Dong et al., 2011), suggesting that MYB transcription factors might be molecular link between circadian clock and stress responses. We also showed that suppression of OsRACK1A activated several known stress-related kinases, such as OsSIK1, OsMAPK5, and OsCPK4 (Fig. 6b). These genes have been reported to be induced by cold, drought, salinity, ABA, and other abiotic stresses. Transgenic plants overexpressing these genes exhibited enhanced tolerance to various stresses (Xiong and Yang, 2003; Ouyang et al., 2010; Campo et al., 2014). In addition, we showed that expression of OsRMC, which negatively regulates salt-stress tolerance in rice (Serra et al., 2013), was suppressed in the RiTL4-2 line (Fig. 6b). Although the signal transduction pathway involving these gene products is unclear, we suggest that OsRACK1A participates in abiotic stress pathways, directly or indirectly, by altering the expression of these stress-related genes.

\section{Conclusions}

In summary, results presented in this study demonstrate that OsRACK1A functions as a stress-responsive gene and OsRACK1A RNAi transgenic rice can significantly improve salt stress tolerance through ABA-dependent and -independent pathway. As a negative regulator of salt stress response, OsRACK1A expresses rhythmically under normal conditions and shows the loss of cycling under salt stress. Although OsRACK1A interacts with many salt-responsive proteins, no directly evidence links OsRACK1A protein to salt stress related transcription 
factors, such as DREB and AP2/ERF. Further investigations on the identification of the functions of OsRACK1A interaction proteins will be helpful to elucidate the mechanism of OsRACK1A in regulating salt stress tolerance.

\section{Additional files}

Additional file 1: Table S2. Primers used for the qRT-PCR analysis of various genes. Figure S1. Public microarray data showing OsRACK1A (A) and OsRACK1B (B) expression is controlled by a circadian clock (http:/ www.ebi.ac.uk/arrayexpress/experiments/E-MTAB-275/). OsRACK1A expression in rice leaves under $16 \mathrm{~h}$ light/ $8 \mathrm{~h}$ dark (LD) or constant light (LL) conditions and under $\mathrm{NaCl}$ treatment (C). Figure S2. OsNCED gene expression in rice leaves under $150 \mathrm{mM} \mathrm{NaCl}$ treatment for $12 \mathrm{~h}$. Figure S3. Quantitative RT-PCR analysis of the expression of OsRACK1 interactors in response to salt stress. (DOCX $356 \mathrm{~kb}$ )

Additional file 2: Table S1. Identification of OsRACK1A interacting proteins. (XLSX $22 \mathrm{~kb})$

\section{Abbreviations}

ABA: Abscisic acid; AP2/ERF: Apetala2/ethylene responsive factor; BMAL1: Brain and muscle arnt-like protein-1: BR: Brassinosteroid; DREB: Dehydration responsive element binding protein; ERFs: Ethylene response factors; GA: Gibberellin; $\mathrm{H}_{2} \mathrm{O}_{2}$ : Hydrogen peroxide; IAA: Indole-3acetic acid; MDA: Malondialdehyde; NCED: 9-cis-epoxycarotenoid dioxygenase; NTL: Non-transgenic line; OeTL: Overexpressing-transgenic line; qPCR: Quantitative PCR; RACK1: Receptor for activated C kinase 1; RiTL: RNA interference- transgenic line; ROS: Reactive oxygen species; SOS: salt overly sensitive; WD40: Tryptophan-aspartic acid 40; ZT: Zeitgeber time

\section{Acknowledgments}

We acknowledge Miss Min Li and Dr. Yujie Fang (Yangzhou University) for their suggestions during this study.

\section{Funding}

This work was supported by the National Science Foundation of China (31271622, 31422047, 31601230, and 31761130073), Natural Science Research Project for Colleges and Universities in Jiangsu Province (16KJB210013), the Jiangsu Province College Students Innovation Training Program in 2016 (X20160741)

\section{Availability of data and materials}

All data supporting the conclusions of this article are provided within the article (and its additional files)

\section{Authors' contribution}

$J, W X$ and DZ conceived and designed the experiments. DZ and YW performed plasmid construction and phenotypic analyses, quantitative realtime RT-PCR and western-blot assay. JS, JY and YG performed yeast two hybrid and co-immunoprecipitation (Co-IP) experiment. DZ, YW, DL, and WX analyzed data. DZ, YW and JL wrote article. All authors read and approved the final manuscript.

\section{Ethics approval and consent to participate}

Not applicable.

\section{Consent for publication}

Not applicable.

\section{Competing interests}

The authors declare that they have no competing interests.

\section{Publisher's Note}

Springer Nature remains neutral with regard to jurisdictional claims in published maps and institutional affiliations.

\section{Author details}

Jiangsu Key Laboratory of Crop Genetics and Physiology/Co-Innovation Center for Modern Production Technology of Grain Crop, Yangzhou University, Yangzhou 225009, Jiangsu, China. ${ }^{2}$ College of Life Sciences, Fujian Agriculture and Forestry University, Jinshan, Fuzhou 350002, China. ${ }^{3}$ Department of Biological Engineering, Huanghuai University, Zhumadian 463000, Henan, China. ${ }^{4}$ Department of Biology, Southern University of Science and Technology, Shenzhen 518055, China.

Received: 27 February 2018 Accepted: 4 July 2018

Published online: 02 August 2018

\section{References}

Arnon DI (1949) Copper enzymes in isolated chloroplasts. Polyphenoloxidase in Beta vulgaris Plant Physiol 24:1-15

Bates LS, Waldren RP, Teare ID (1973) Rapid determination of free proline for water-stress studies. Plant Soil 39:205-207

Campo S, Baldrich P, Messeguer J, Lalanne E, Coca M, San Segundo B (2014) Overexpression of a calcium-dependent protein kinase confers salt and drought tolerance in Rice by preventing membrane lipid peroxidation. Plant Physiol 165:688-704

Chen JG, Ullah H, Temple B, Liang J, Guo J, Alonso JM et al (2006) RACK mediates multiple hormone responsiveness and developmental processes in Arabidopsis. J Exp Bot 57:2697-2708

Cheng Z, Li JF, Niu Y, Zhang XC, Woody OZ, Xiong Y et al (2015) Pathogensecreted proteases activate a novel plant immune pathway. Nature 521:213216

Cutler SR, Rodriguez PL, Finkelstein RR, Abrams SR (2010) Abscisic acid: emergence of a core signaling network. Annu Rev Plant Biol 61:651-679

Dhindsa RS, Matowe W (1981) Drought tolerance in two mosses: correlated with enzymatic defence against lipid peroxidation. J Exp Bot 32:79-91

Dong MA, Farre EM, Thomashow MF (2011) Circadian Clock-Associated 1 and Late Elongated Hypocotyl regulate expression of the C-Repeat Binding Factor (CBF) pathway in Arabidopsis. Proc Natl Acad Sci U S A 108:7241-7246

Dossa K, Wei X, Li D, Fonceka D, Zhang Y, Wang L et al (2016) Insight into the AP2/ERF transcription factor superfamily in sesame and expression profiling of DREB subfamily under drought stress. BMC Plant Biol 16:171

Dubouzet JG, Sakuma Y, Ito Y, Kasuga M, Dubouzet EG, Miura S et al (2003) OsDREB genes in rice, Oryza sativa L., encode transcription activators that function in drought-, high-salt- and cold-responsive gene expression. Plant J 33:751-763

Grundy J, Stoker C, Carré IA (2015) Circadian regulation of abiotic stress tolerance in plants. Front Plant Sci 6:648

Guo J, Chen JG (2008) RACK1 genes regulate plant development with unequal genetic redundancy in Arabidopsis. BMC Plant Biol 8:108

Guo J, Wang J, Xi L, Huang WD, Liang J, Chen JG (2009) RACK1 is a negative regulator of ABA responses in Arabidopsis. J Exp Bot 60:3819-3833

Guo J, Wang S, Valerius O, Hall H, Zeng Q, Li JF et al (2011) Involvement of Arabidopsis RACK1 in protein translation and its regulation by abscisic acid. Plant Physiol 155:370-383

Guo R, Sun W (2017) Sumoylation stabilizes RACK1B and enhance its interaction with RAP2.6 in the abscisic acid response. Sci Rep 7:44090

Hayes KR, Beatty M, Meng X, Simmons CR, Habben JE, Danilevskaya ON (2010) Maize global transcriptomics reveals pervasive leaf diurnal rhythms but rhythms in developing ears are largely limited to the core oscillator. PLoS One $5:$ :e12887

He H, Li J (2008) Proteomic analysis of phosphoproteins regulated by abscisic acid in rice leaves. Biochem Biophys Res Commun 371:883-888

Hu H, Dai M, Yao J, Xiao B, Li X, Zhang Q et al (2006) Overexpressing a NAM, ATAF, and CUC (NAC) transcription factor enhances drought resistance and salt tolerance in rice. Proc Natl Acad Sci U S A 103:12987-12992

Ishikawa R, Aoki M, Kurotani KI, Yokoi S, Shinomura T, Takano M et al (2011) Phytochrome B regulates heading date 1 ( $\mathrm{Hd} 1$ )-mediated expression of rice florigen Hd3a and critical day length in rice. Mol Gen Genomics 285:461-470

luchi S, Kobayashi M, Taji T, Naramoto M, Seki M, Kato T et al (2001) Regulation of drought tolerance by gene manipulation of 9-cis-epoxycarotenoid dioxygenase, a key enzyme in abscisic acid biosynthesis in Arabidopsis. Plant J 27:325-333

Jończyk M, Sobkowiak A, Trzcinska-Danielewicz J, Skoneczny M, Solecka D, Fronk J, Sowiński P (2017) Global analysis of gene expression in maize leaves 
treated with low temperature. II. Combined effect of severe cold $\left(8^{\circ} \mathrm{C}\right)$ and circadian rhythm. Plant Mol Biol 95:279-302

Ke Y, Han G, He H, Li J (2009) Differential regulation of proteins and phosphoproteins in rice under drought stress. Biochem Biophys Res Commun 379:133-138

Khan S, Rowe SC, Harmon FG (2010) Coordination of the maize transcriptome by a conserved circadian clock. BMC Plant Biol 10:126

Kim WY, Ali Z, Park HJ, Park SJ, Cha JY, Perez-Hormaeche J et al (2013) Release of SOS2 kinase from sequestration with GIGANTEA determines salt tolerance in Arabidopsis. Nat Commun 4:1352

Kundu N, Dozier U, Deslandes L, Somssich IE, Ullah H (2013) Arabidopsis scaffold protein RACK1A interacts with diverse environmental stress and photosynthesis related proteins. Plant Signal Behav 8:e24012

Li DH, Liu H, Yang YL, Zhen PP, Liang JS (2009) Down-regulated expression of RACK1 gene by RNA interference enhances drought tolerance in rice. Rice Sci 16:14-20

Li HW, Zang BS, Deng XW, Wang XP (2011) Overexpression of the trehalose-6phosphate synthase gene OsTPS1 enhances abiotic stress tolerance in rice. Planta 234:1007-1018

Mao D, Chen C (2012) Colinearity and similar expression pattern of rice DREB1s reveal their functional conservation in the cold-responsive pathway. PLoS One 7:e47275

Matsubara K, Yamanouchi U, Nonoue Y, Sugimoto K, Wang ZX, Minobe Y et al (2011) Ehd3, encoding a plant homeodomain finger-containing protein, is a critical promoter of rice flowering. Plant J 66:603-612

McCahill A, Warwicker J, Bolger GB, Houslay MD, Yarwood SJ (2002) The RACK1 scaffold protein: a dynamic cog in cell response mechanisms. Mol Pharmaco 62:1261-1273

Mukhopadhyay P, Tyagi AK (2015) OsTCP19 influences developmental and abiotic stress signaling by modulating ABI4-mediated pathways. Sci Rep 5: 9998

Nakashima A, Chen L, Thao NP, Fujiwara M, Wong HL, Kuwano M et al (2008) RACK1 functions in rice innate immunity by interacting with the Racl immune complex. Plant Cell 20:2265-2279

Nambara E, Marion-Poll A (2005) Abscisic acid biosynthesis and catabolism. Annu Rev Plant Biol 56:165-185

Oh SJ, Kim YS, Kwon CW, Park HK, Jeong JS, Kim JK (2009) Overexpression of the transcription factor AP37 in rice improves grain yield under drought conditions. Plant Physiol 150:1368-1379

Ouyang SQ, Liu YF, Liu P, Lei G, He SJ, Ma B et al (2010) Receptor-like kinase OsSIK1 improves drought and salt stress tolerance in rice (Oryza sativa) plants. Plant J 62:316-329

Park DH, Somers DE, Kim YS, Choy YH, Lim HK, Soh MS et al (1999) Control of circadian rhythms and photoperiodic flowering by the Arabidopsis GIGANTEA gene. Science 285:1579-1582

Park HJ, Kim WY, Yun DJ (2016a) A New Insight of Salt Stress Signaling in Plant. Mol Cells 39:447-459

Park HJ, Qiang Z, Kim WY, Yun DJ (2016b) Diurnal and circadian regulation of salt tolerance in Arabidopsis. J Plant Biol 59:569-578

Qin QL, Liu JG, Zhang Z, Peng RH, Xiong AS, Yao QH et al (2006) Isolation, optimization, and functional analysis of the cDNA encoding transcription factor OsDREB1B in Oryza Sativa L. Mol Breeding 19:329-340

Robles MS, Boyault C, Knutti D, Padmanabhan K, Weitz CJ (2010) Identification of RACK1 and protein kinase Calpha as integral components of the mammalian circadian clock. Science 327:463-466

Serra TS, Figueiredo DD, Cordeiro AM, Almeida DM, Lourenço T, Abreu IA et al (2013) OsRMC, a negative regulator of salt stress response in rice, is regulated by two AP2/ERF transcription factors. Plant Mol Biol 82:439-455

Shi S, Chen W, Sun W (2011) Comparative proteomic analysis of the Arabidopsis cbl1 mutant in response to salt stress. Proteomics 11:4712-4725

Thines B, Harmon FG (2011) Four easy pieces: mechanisms underlying circadian regulation of growth and development. Curr Opin Plant Biol 14:31-37

Umezawa T, Nakashima K, Miyakawa T, Kuromori T, Tanokura M, Shinozaki K et al (2010) Molecular basis of the core regulatory network in ABA responses: sensing, signaling and transport. Plant Cell Physiol 51:1821-1839

Urano D, Czarnecki O, Wang X, Jones AM, Chen JG (2015) Arabidopsis receptor of activated $\mathrm{c}$ kinase 1 phosphorylation by with no lysine8 kinase. Plant Physiol 167:507-516

Wilkins O, Bräutigam K, Campbell MM (2010) Time of day shapes Arabidopsis drought transcriptomes. Plant J 63:715-727
Xiong L, Schumaker KS, Zhu JK (2002) Cell signaling during cold, drought, and salt stress. Plant Cell 14(Suppl):S165-S183

Xiong $L$, Yang $Y$ (2003) Disease resistance and abiotic stress tolerance in rice are inversely modulated by an abscisic acid-inducible mitogen-activated protein kinase. Plant Cell 15:745-759

Xue $W$, Xing $Y$, Weng $X$, Zhao $Y$, Tang W, Wang $L$ et al (2008) Natural variation in Ghd7 is an important regulator of heading date and yield potential in rice. Nat Genet 40:761-767

Yang A, Dai X, Zhang WH (2012) A R2R3-type MYB gene, OsMYB2, is involved in salt, cold, and dehydration tolerance in rice. J Exp Bot 63:2541-2556

Yang C, Ma B, He SJ, Xiong Q, Duan KX, Yin CC et al (2015) Maohuzi6/Ethylene Insensitive3-Like1 and Ethylene Insensitive3-Like2 regulate ethylene response of roots and coleoptiles and negatively affect salt tolerance in Rice. Plant Physiol 169:148-165

Yoshida T, Mogami J, Yamaguchi-Shinozaki K (2014) ABA-dependent and ABAindependent signaling in response to osmotic stress in plants. Curr Opin Plant Biol 21C:133-139

Zhang D, Chen L, Li D, Lv B, Chen Y, Chen J et al (2014) OsRACK1 is involved in abscisic acid- and $\mathrm{H} 2 \mathrm{O} 2$-mediated signaling to regulate seed germination in rice (Oryza sativa, L.). PLoS One 9:e97120

Zhang D, Zhou Y, Yin J, Yan X, Lin S, Xu W et al (2015) Rice G-protein subunits qPE9-1 and RGB1 play distinct roles in abscisic acid responses and drought adaptation. J Exp Bot 66:6371-6384

Zhang DP, Chen L, Lv B, Liang JS (2013) The scaffolding protein RACK1: a platform for divers functions in the plant kingdom. Plant Biology Soil Health $1: 7-13$

Zhang L, Tian LH, Zhao JF, Song Y, Zhang CJ, Guo Y (2009) Identification of an Apoplastic protein involved in the initial phase of salt stress response in Rice root by two-dimensional electrophoresis. Plant Physiol 149:916-928

Zhu G, Ye N, Zhang J (2009) Glucose-induced delay of seed germination in rice is mediated by the suppression of ABA catabolism rather than an enhancement of ABA biosynthesis. Plant Cell Physiol. 50:644-651

Zhu JK (2003) Regulation of ion homeostasis under salt stress. Curr Opin Plant Biol 6:441-445

\section{Submit your manuscript to a SpringerOpen ${ }^{\circ}$ journal and benefit from:}

- Convenient online submission

- Rigorous peer review

- Open access: articles freely available online

- High visibility within the field

Retaining the copyright to your article

Submit your next manuscript at $>$ springeropen.com 